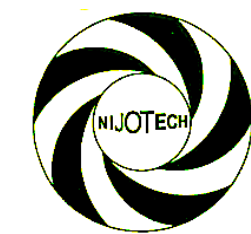

Nigerian Journal of Technology (NIJOTECH)

Vol. 39, No. 2, April 2020, pp. $\mathbf{5 0 0}$ - $\mathbf{5 0 5}$

Copyright@ Faculty of Engineering, University of Nigeria, Nsukka

Print ISSN: 0331-8443, Electronic ISSN: 2467-8821

www.nijotech.com

http://dx.doi.org/10.4314/njt.v39i2.20

\title{
ASSESSMENT OF INTERNET SERVICE PROVIDED USING UMTS OPERATORS AT THE UNIVERSITY OF ILORIN MAIN CAMPUS
}

\author{
J. Akanni', ${ }^{1,}$, A. A. Isa ${ }^{2}$, R. A. Alao ${ }^{3}$ and C. T. Thomas ${ }^{4}$ \\ $\mathbf{1 , 2 , 3}$ Dept of EleCtrical\&Electronic EngineERING, UNIVERSITY OF ILORIN, ILORIN, KWARA STATE, NIGERIA \\ 4, DEPT OF ElECTRICAL AND INFORMATION ENGINEERING, ACHIEVERS UNIVERSITY, OWO, ONDO STATE, NIGERIA \\ E-mail addresses; 1 jimaka2005@gmail.com, 2 abdurrhaman49@gmail.com, \\ 3alao.ra@unilorin.edu.ng, ${ }^{4}$ cornelt.elect@gmail.com
}

\begin{abstract}
Over the years the need for mobile broadband had seen a great increment due to the demand of internet mobile users. In this research work, data size for Internet operation on UMTS mobile network operators on the University of Ilorin Campus was assessed. The study assessed three UMTS network operators using an Infinix T627 android smart phone and RantCell App. to measure the download and upload at the selected points on the University of Ilorin Campus. It was observed that the number of active subscribers with their relative position in a cell have a great effect on the performance of the networks and therefore, the authors recommend the need for the operators to improve their data sizes so as to enhance users' satisfaction.
\end{abstract}

Keywords: GSM, CDMA, ISP, PS, UMTS.

\section{INTRODUCTION}

A great number of active mobile subscribers have increased the use of mobile device; from voice activities to internet access activities for social and economic intent leading to a tremendous demand for mobile services [1].According to the most recently measured period, there were almost 50 million mobile internet users in Nigeria, and mobile phone internet usage is particularly popular. In 2018, Nigeria had 92.3 million internet users. This number is expected to rise to 187.8 million internet users in 2023. Internet penetration accounted for 47.1 percent of the population in 2018 and is set to reach 84.5 percent in 2023[2].

Wireless technology offers more flexible and inexpensive ways of communication and also having four key comparative advantages over the wired technology - increased efficiency, high availability, greater flexibility and mobility for users at a far better reduced cost of installation and maintenance [3]. They are usually classified according to their generation, which largely specifies the type of services and the data speed for each class of technologies [3]. These classes range from $0 \mathrm{G}$ to $4 \mathrm{G}$ and also up to the proposed $5 \mathrm{G}$ to be launched in the year 2020.

$2 \mathrm{G}$ was originally designed for voice communication only but data capability was added, [4].As a result of limited data-handling capabilities of second Generation(2G), third Generation (3G) mobile communications systems of Universal Mobile Telecommunications System (UMTS) standard were developed in order to have higher bit-rate services that enable high-quality images and video to be transmitted, and to provide access to Internet with higher data rates. UMTS data growth is driven by high-speed radio capability, flat-rate pricing schemes, and simple device installation, and its introduction has marked the transition of mobile communications from voice-dominated networks to packet-data ones [5].

Anwar et al., [6] comes up with design and optimization of conditions for 3G technologies by evaluating the downlink and uplink throughput and spectral efficiency performance of the standard UMTS network for different service scenarios of user and different technologies. The data for the research was obtained and compiled from different operators

* Corresponding author, tel: +234 8030530170 
in Asia, America and Europe but the network operators did not allow the authors to analyze the performance of their networks, though it was observed based on the authors investigation from the data obtained for different type of service scenarios such as File Transfer Protocol (FTP), Multimedia Messaging (MMS) and web; which shows that throughput for FTP was highest with lower latency while throughput for web was lowest but with higher latency. The limitation of their research is that the information is operator based not user's real time data that will allow for better optimization and robust planning for future purpose [6].

Fallah et al., [7] in their study presented a multivariate analysis such as correlation, factor analysis, multidimensional scaling, cluster analysis and correspondence analysis to determine the performance of a UMTS network in terms of packet loss, latency, throughput (download and upload) and utilization. The research showed that real time parameters or indicators of a Packet Switched (PS) network such as UMTare analyzed both in short and long run basis to help network administrator predict the potential trend of changes of network performance in advance. Their research is a simulation work and the data are stochastically generated; so the experience of the users might be different[7].

Uzun \& Abul [8]developed an internet speed analysis for mobile Internet Service Provider to conduct a research on end-to-end internet speed analysis of mobile networks with MapReduce in Turkey. The test system run periodically in several areas with actual usage scenarios and trace Transmission Control Protocol (TCP) packets in terms of download and upload were computed. Scalability of user experience amongst the selected region and even better automatic detection of problem (Denial-ofService, DoS) were addressed in the research. The research focuses only on one Internet Service Provider (ISP)[8].

Suharyanto, Simanjuntak, \& Gunawan [9] performed a comparative internet analysis on service providers in Batman, parameters such as delay, jilters, throughput, download and upload where measured with some android apps(Network cell info, Oakla speed test and Speed test master). The first procedure was by obtaining some certain information from the network providers after which measurements were conducted during some periods of the day. The research shows that what the providers claimed to be the internet performances differ from what is usually obtained by the users. The experiment was user based. The limitation in their research is that only seven set of iterations were employed[9].

The rest of the paper is organized as follows: Section 2 presents Universal Mobile Telecommunication Systems (UMTS); its overview and architecture. Section 3 presents the methodology used to conduct the research. The results and discussion was represented in section 4 and finally the conclusion is presented in section 5 .

\section{UNIVERSAL MOBILE TELECOMMUNICATION SYSTEMS (UMTS)}

\subsubsection{UMTS Overview}

UMTS is a third Generation (3G) wireless communication system that act as an upgrade to the second Generation (2G) communication technologies and is an enhanced version of GSM GPRS and EDGE [10]. The GSM network was originally launched to provide voice capabilities to subscribers but as needed to support the increasing number of subscribers while providing high speed data services, the Third Generation Partnership Programme (3GPP) was formed to oversee the implementation of a system that could offer support to those services [11].

UMTS uses Code Division Multiple Access (CDMA) in which a user is assigned a unique code sequence to encode its information bearing signal, the receiver knowing the code sequences of the user; decode a received signal after reception and recover the original signal [12].

\subsection{Network Architecture}

When wireless communication was introduced, voice was the priority as depicted by the GSM architecture, but recently data are playing more important role in wireless networks, leading to the convergence of voice and high speed data services into a single system under the UMTS standardization[13]. In the architectural design, the UMTS radio access network, Universal Terrestrial Radio Access Network (UTRAN) was a complete new development, but most of all the other components of the GSM core network were embedded into the UMTS architecture with a few changes[13].

The UMTS network architecture is divided into three sections. These sections are: the UE (User Equipment) made of Universal Subscriber Identity 
Module (USIM) and Mobile Equipment (ME) that interfaces with the user; the UTRAN (UMTS Terrestrial Radio Access Network) consisting of Node $B$ and Radio Network Controller (RNC) that handles all radio related functionality and the Core Network (CN) that comprises of Mobile Switching Centre (MSC), Visitors Location Register (VLR) and Servicing GPRS Support Node (SGSN) which is responsible for transport functions such as switching, routing calls and data and tracking users. Figure1 shows the UMTS basic network architecture. The technology used in UTMS is Wideband Code Division Multiple Access (WCDMA) which provides significant higher bandwidth compared to the ordinary CDMA. A more designed principle is to logically spilt the architecture into 'access stratum', for equipment and functionality task of the access technique (e.g. radio-related functionality), and 'non-access strata'. The access stratum includes protocols between the user equipment terminal and the access network, and between the access network and the serving core network. While the non-access strata support the transfer of specific radio-related data resources, the latter are independent of the specific radio structure of the access network [14].

\section{METHODOLOGY}

\subsection{Study Area}

University of Ilorin cited in Ilorin city, Kwara State, Nigeria is located between latitude $8.48^{\circ} \mathrm{N}$ and $8.49^{\circ} \mathrm{N}$ and longitude $4.44^{\circ} \mathrm{E}$ and $4.5^{\circ} \mathrm{E}$ (Google Maps, 2019). It covers an approximated land mass of 5000 hectares. It is characterized by complex terrain due to presence of hills and valleys and forest within the Campus. The University possess a staff strength of about 4, 474 with over 48, 000 undergraduate and over 5, 000 postgraduate students[15]. The selected point on the study location are the University Administrative Building Complex otherwise called the Senate Building $\left(8^{\circ} 28^{\prime} 46.24^{\prime \prime} \mathrm{N}\right.$ and $\left.4^{\circ} 40^{\prime 2} 24.73^{\prime \prime} \mathrm{E}\right)$ labelled $\mathrm{X}$, the Block $8\left(8^{\circ} 29^{\prime} 1.26^{\prime \prime} \mathrm{N}\right.$ and $\left.4^{\circ} 40^{\prime} 28.19^{\prime \prime} \mathrm{E}\right)$ labelled $Y$ and the Faculty of Law $\left(8^{\circ} 29^{\prime} 1.38^{\prime \prime} \mathrm{N}\right.$ and $4040^{\prime} 17.68^{\prime \prime}$ E) labelled $Z$. Three network radio towers on the study location named $A, B$ and $C$ is considered. Figure 2 shows the Google Map of the study location.

\subsection{Materials Employed}

The materials used to conduct the research includes three Infinix T627 android smart phones with three GSM SIM cards which served as the gateway in accessing the network service providers, the RantCell App for measuring and obtaining the download and upload rate of a UMTS GSM network, a Global Position System (GPS) for obtaining coordinates as well elevation of the study location. A Personal Computer (PC) was also used to import the data measured by the Infinix T627 smart phones.

\subsection{Experimental Procedures}

To assess the performance of UMTS data service on the University of Ilorin Campus and for easy navigation of the Campus, a Google map of University of Ilorin Campus (Figure 2)was obtained and used to identify the selected location and locating the Node- $\mathrm{B}$ of the service providers.

Two cases were considered for the measurement. The first case called the morning phase, measurement was carried out at 12 am and 7 am with measuring equipment at the three selected locations. In this case the download and upload rates of the three service providers were measured for thirty days. The objective was to obtain an average download and upload rate of the service provider for better evaluation. In the second case called the afternoon phase, measurement was conducted at 12 noon and 4 pm with the measuring equipment. The download and upload rates were also measured and recorded and there after imported to a PC. For unbiased, independent and reliable data, several tests were conducted in different days, at selected time on the study location.

\section{RESULTS AND DISCUSSION}

Figure 3 through Figure 5 show the average download data size rate per period at each of the selected point on the study location. Location $X$ has a higher data size for all the operators. But in each of the location operator $C$ data size is just fairly above the $384 \mathrm{kbps}$ which is the minimum value for a UMTS mobile network. Except operator $A$ at location $X$, none of the operators is performing at a data rate of $720 \mathrm{kbps}$ which is the minimum 


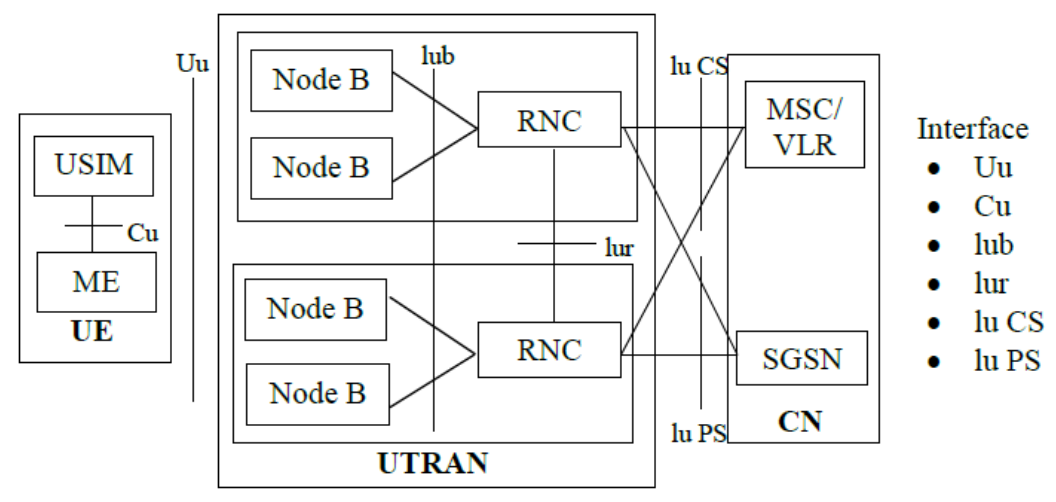

Figure 1: UMTS Network Architecture

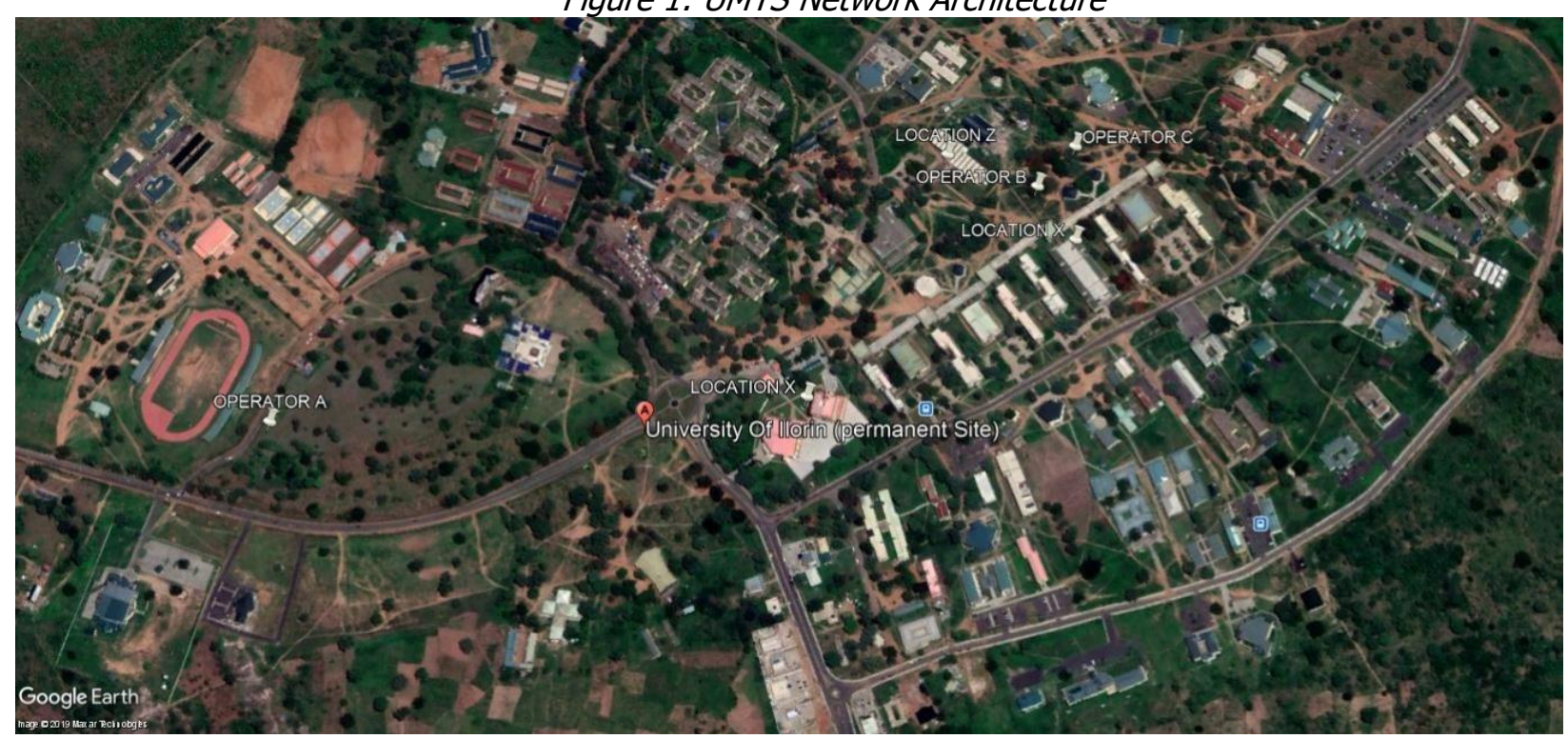

Figure 2: Google Earth Map of the Study Location (University of Ilorin Main Campus)

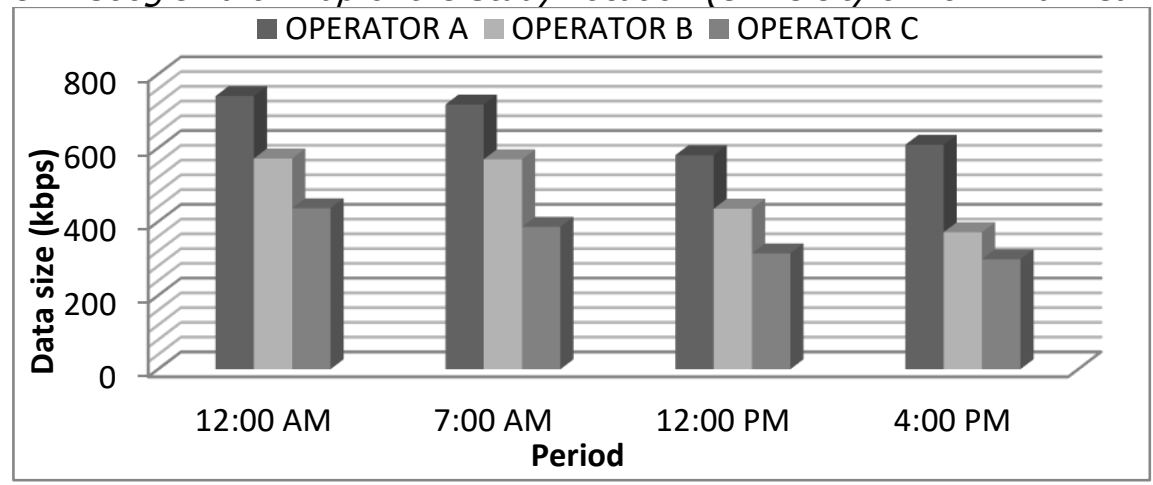

Figure 3: Average download data size rate at location $X$

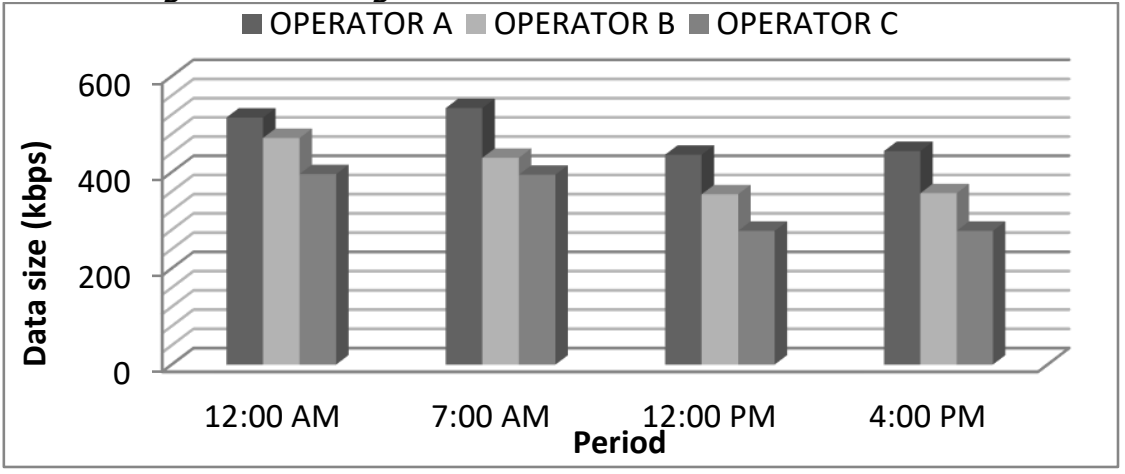

Figure 4: Average download data size rate at location $Y$ 
value quoted for live streaming and other related enhanced Internet operations.

Figures 6 through Figure 8 depict the average upload data size rate; it is expected that the value for the upload data size should also be $384 \mathrm{kbps}$ for a UMTS mobile network. However none of the operators at each study location points (Figure 6 through Figure 8) achieved this.

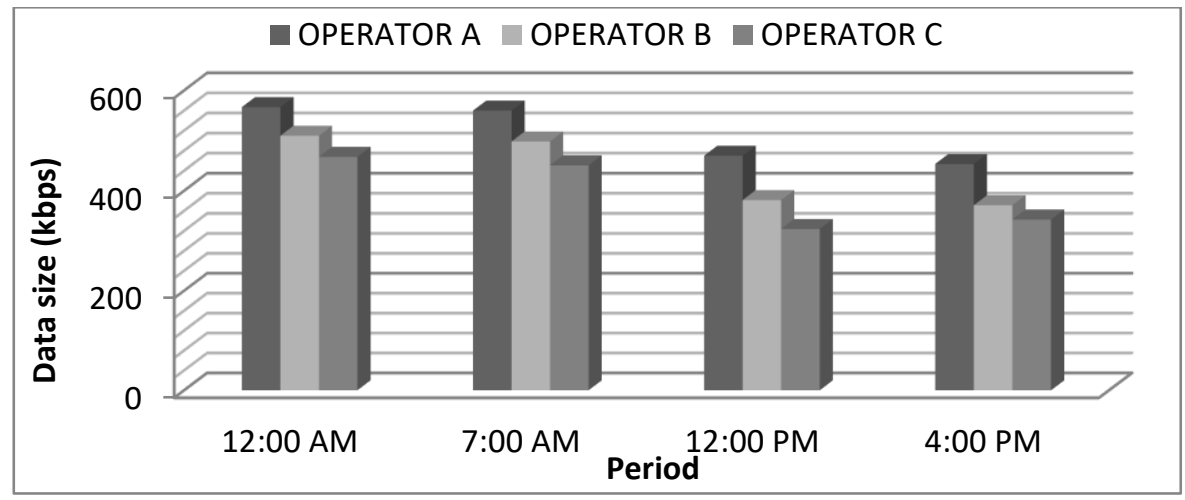

Figure 5: Average download data size rate at location $Z$

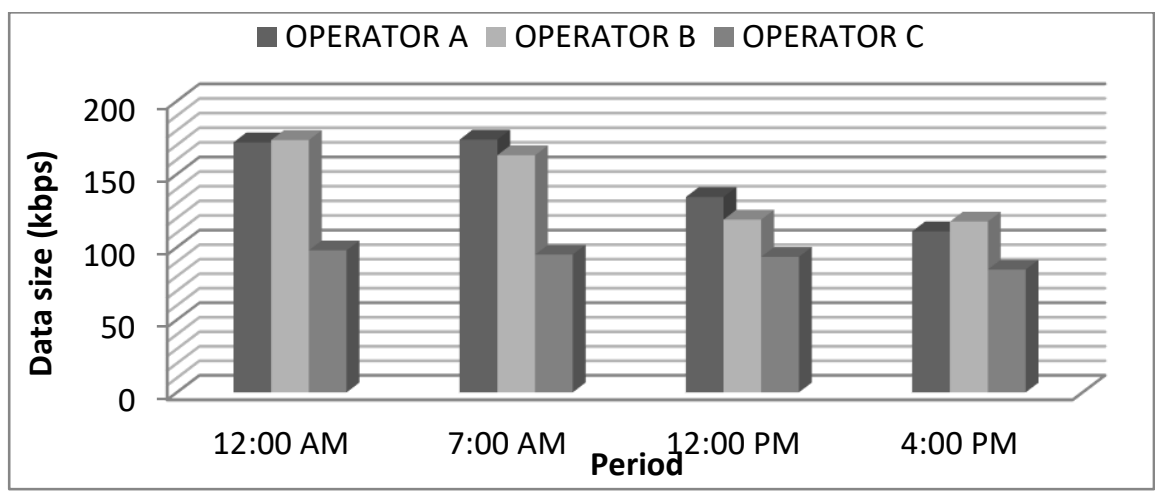

Figure 6: Average upload data size rate at location $X$

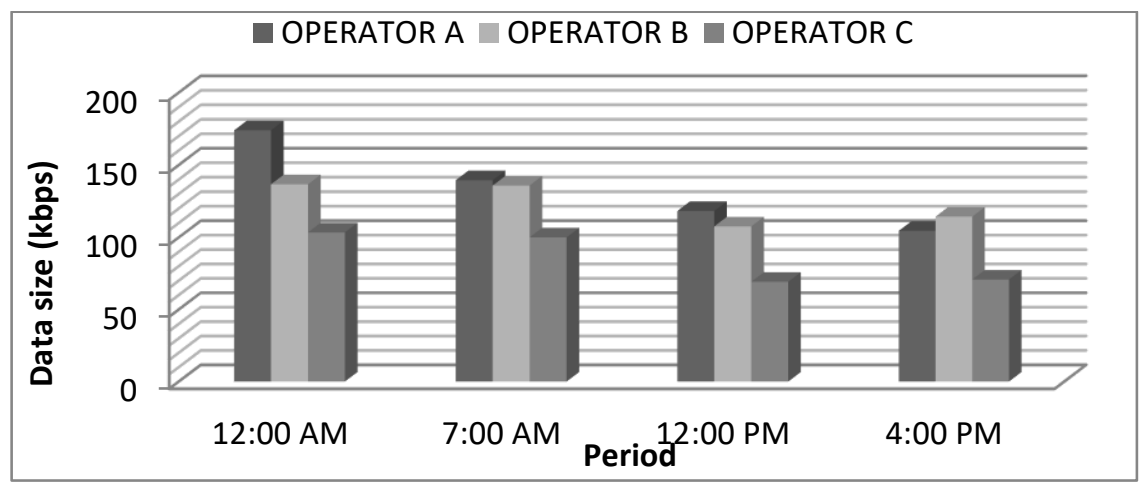

Figure 7: Average upload data size rate at location $Y$

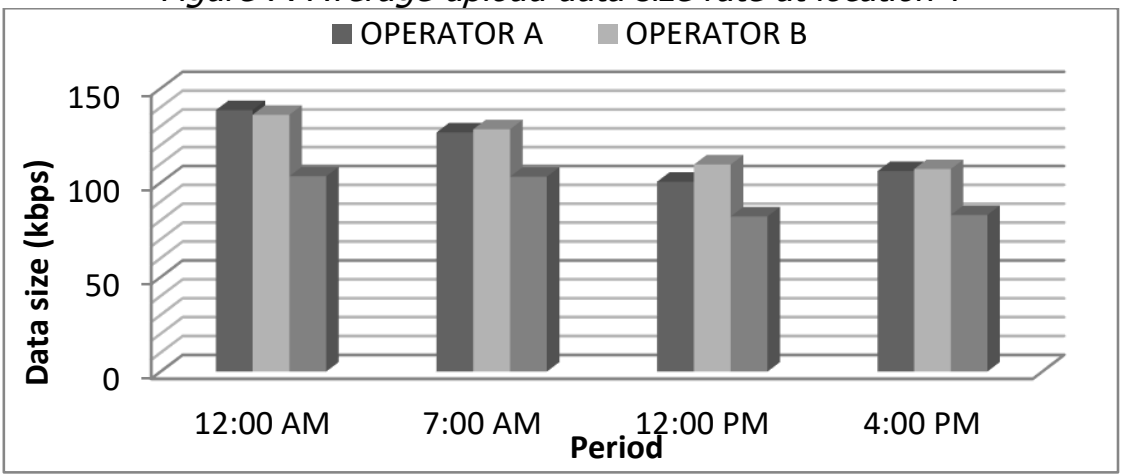

Figure 8: Average upload data size rate at location $Z$ 


\section{CONCLUSIONS}

The study concluded that most of the service providers' network can be used for basic internet operation such as script, text and animated object operation but for heavy operations such as live streaming, internet video calls etc., the service providers' data size rate is not achieved and also the number of active users together with the relative position of the user in a cell has a great significance effect on the data performance of a mobile network. It however advisable if the user can move closer to the service provider's transmitter for better signal so as to have a better data rate size, and service providers should improve the data size of their network to meet the require UMTS standard.

\section{REFERENCES}

[1] B. M. Kuboye, "Evaluation of Broadband Network Performance in Nigeria," Int. $J$. Commun. Netw. Syst. Sci., no. 10, pp. 199207, 2017.

[2] J. Clement, "Number of Internet Users in Nigeria from 2017 to 2023," 2019. [Online]Available:

https://www.statista.com/statistics/183849/in ternet-users-nigeria/ [Accessed: ]

[3] G. P. Kaur, J. Birla, and J. Ahlawat, "Generations of Wireless Technology," Int. J. Comput. Sci. Manag. Stud., vol. 11, no. 02, pp. 176-180, 2011.

[4] M. Uzun and O. Abul, "End-to-end internet speed analysis of mobile networks with mapReduce," in 2016 International Symposium on Networks, Computers and Communications (ISNCC), 2016, pp. 1-6.

[5] C. J. A. Martins, "Analysis of data services performance in UMTS networks using data analytics,"M. S. thesis, College of Electrical and Computer Engineering, Tecnico Lisboa, 2015. [Online] Available: https://grow.tecnico.ulisboa.pt/wpcontent/uploads/2016/01/2015 CarlosMartins .pdf

[6] T. Anwar and L. Wern Li, "Performance Analysis of 3G Communication Network," ITB
J. Inf. Commun. Technol., vol. 2, no. 2, pp. 130-157, 2008.

[7] Y. O. and M. H. Fallah, "A Performance Analysis for UMTS Packet Switched Network Based on Multivariate KPIs," Int. J. NextGeneration Networks(IJNGN), vol. 2, no. 1, pp. 80-94, 2010.

[8] M. Uzun and O. Abul, "End-to-end internet speed analysis of mobile networks with mapReduce," 2016 Int. Symp. Networks, Comput. Commun. ISNCC 2016, 2016.

[9] C. E. Suharyanto, P. Simanjuntak, and F. E. Gunawan, "Quality of Service of GSM . A Comparative Internet Access Analysis of Provider in Batam," IEEE Int. J. Open Inf. Technol., vol. 5, no. 6, pp. 26-32, 2017.

[10] P. Ian, "3G UMTS / WCDMA Network Architecture," Cellular/Mobile Communications, 2011. [Online]. Available: https://www.radio-

electronics.com/info/cellulartelecomms/umts/ umts-wcdma-network-architecture.php. [Accessed: 05-Nov-2018].

[11] P. A. Ochang and P. J. Irving, "Evolutionary Analysis of GSM, UMTS and LTE Mobile Network Architectures," world Sci. New, vol. 54, pp. 27-39, 2016.

[12] R. Prasad and T. Ojanpera, "An overview of CDMA evolution toward wideband CDMA," IEEE Commun. Surv., vol. 1, no. 1, pp. 2-29, 2000.

[13] M. Sauter, From GSM to LTE: An Introduction to Mobile Networks and Mobile Broadband. 2011.

[14] A. S. Thethi and R. . Sawhney, "Performance Evaluation of QoS parameters in UMTS Network Using Qualnet," Int. J. Distrib. Parallel Syst., vol. 1, no. 2, pp. 57-66, 2010.

[15] University of Ilorin, "About Us," Theatre Communications Group, 2019. [Online]. Available:

http://www.tcg.org/Default.aspx?TabID=196 